\title{
The Usefulness of a Simulated Environment in Ethnographic Research for Gaming and HCI
}

\author{
Noor Fardela Zainal Abidin \\ School of Computer and Mathematical Sciences \\ Auckland University of Technology \\ Auckland, New Zealand \\ dzainala@aut.zc.nz
}

\author{
Robert Wellington \\ School of Computer and Mathematical Sciences \\ Auckland University of Technology \\ Auckland, New Zealand \\ rwelling@aut.ac.nz
}

\begin{abstract}
Ethnography is now a widely used research method in information systems and gaming. It is one of the most in-depth research methods that can capture people's feelings, behavior and opinions by the researcher getting immersed in the study. The main aspect of the research method is gathering the data by being in the 'field', gaining a deep insight by participating and observing the culture being studied. The authors have replaced the 'field' with simulated environments, and although this would tend to infer a less rich or truthful ethnographic study (from a purist's perspective), they reflect on the usefulness in the context of two ongoing research studies. A Simulated Gaming Environment is proving to offer a suitably 'real' experience for the first author's research, and a driving simulator is the only option for the second.
\end{abstract}

Keywords-component; Ethnography, Simulated Gaming Environment, $\mathrm{HCI}$.

\section{INTRODUCTION}

Ethnography is a research method used by researchers to capture an understanding of people's feelings, behavior and opinions by being close to the subjects and getting immersed in the study. It allows the researcher to gain an in-depth understanding of the people, the organisation, and the broader context within which they work. Ethnography relies heavily on up-close, personal experience and the possibility of participating in the research and not just by observing [13]. An ethnographer would conduct the research by interacting with the people not only by observing but also by participating in the activities, from interviews to emotional experience in understanding rituals and cultures [4]. As Myers [3] points out, by participating in the research, the researcher develops an intimate familiarity with the dilemmas, frustration, routines, relationship and risks involved in the study. Ethnography research is most famously used in the area of anthropology and sociology and has evolved into the area of education, public health and has potential for researching any human area of activity [2].

The purpose of this paper is to discuss the potential of using a Simulated Gaming Environment (SGE) as the "field" for ethnographic research. This paper is organized into six sections. Following this introduction, Section 2 discusses the use of ethnography in information systems studies. Section 3 discusses gaming as a part of today's culture. Section 4 argues on the potential of using SGE as the "field" for ethnographic research. Section 5 discusses the prospect of SGE in answering some of the challenges in Ethnographic research. Section 6 includes a summary of two ongoing research projects that are using simulated environments and ethnography at AUT and discusses preliminary results of using this method in the research. The final section is the conclusion.

\section{ETHNOGRAPHY FOR INFORMATION SYSTEMS}

Ethnography in information system has been widely discussed to be an encouraging method in studying the usability of systems, giving information system researchers' rich insight into the human, social and organisational aspects of information systems [3]. To use ethnography is a step in understanding the nature of work that would strengthen the construction of interactive systems. It is also increasingly accepted within the software engineering community that understanding the "social" real world is an important factor in software design. [5]. There are various methods where ethnography can be used in studying software design, and interface design. Refer to Table I.

TABLE I. ETHNOGRAPHY METHODS

\begin{tabular}{|l|l|c|}
\hline \multicolumn{1}{|c|}{ Method } & \multicolumn{1}{|c|}{ Description } & Reference \\
\hline $\begin{array}{l}\text { Concurrent } \\
\text { Ethnography }\end{array}$ & $\begin{array}{l}\text { Ethnography study take place at the } \\
\text { same time a system is design. Usually } \\
\text { systems prototype is developed and } \\
\text { refined based upon the result of study. }\end{array}$ & [6-7] \\
\hline $\begin{array}{l}\text { Quick and } \\
\text { Dirty }\end{array}$ & $\begin{array}{l}\text { Ethnography study is done to provide } \\
\text { general but informed sense of the setting } \\
\text { for designers. It is the only form of } \\
\text { ethnography done when there is limited } \\
\text { time and/or budget. }\end{array}$ & [6-7] \\
\hline $\begin{array}{l}\text { Evaluative } \\
\text { Ethnography }\end{array}$ & $\begin{array}{l}\text { Ethnography study use to evaluate a } \\
\text { new design model. It helps to verify or } \\
\text { validate a new design model or theory. }\end{array}$ & [6-7] \\
\hline $\begin{array}{l}\text { Uses a collection of field methods } \\
\text { intended to provide a reasonable } \\
\text { Ethnography }\end{array}$ & $\begin{array}{l}\text { understanding of users and their } \\
\text { activities given significant time } \\
\text { pressures and limited time in the field. }\end{array}$ & [7-8] \\
\hline $\begin{array}{l}\text { Re- } \\
\text { examining } \\
\text { Previous } \\
\text { Studies }\end{array}$ & $\begin{array}{l}\text { Ethnography study that have been used } \\
\text { in many other areas where previous } \\
\text { studies are re-examined to inform initial } \\
\text { design thinking. }\end{array}$ & [6-7] \\
\hline
\end{tabular}


Evaluative ethnography could be the closest ethnographic method suitable for gaming research. The "restricted domain" in this type of study allows an "evaluative ethnographic study to be performed in a relatively short time frame" [7, p. 5]. Although this tends to draw criticism from ethnography 'purists', but could be considered as a similar step of pragmatism to the movement from 'pure' positivism to post-positivism, where even in the face of an inability to truly generalize to a universal truth, the methodological rigour is applied to more constrained contexts. An example of evaluative ethnography was applied to virtual environments where the authors suggested that the design of such environments requires a clear study of participants at the very early stages of the project [Crabtree et al. 1999 as cited by 9]. Gouveia \& Gouveia [9] examined the use of evaluative ethnography for design practices in particular to "a visualization design for sharing knowledge (ViDESK)". They also discussed how presence can be assessed with the system itself. Results from the ethnographic approach and quantitative research enabled them to reach a number of useful conclusions that enable them to assess the system and list a number of design requirements.

Lehmann, Freedman, Massad, \& Dintzis [10] conducted a controlled, factorial design study to evaluate the effects of integrating a computer-based atlas in their laboratory courses. In this controlled environment, they also incorporated an ethnographer to observe and record data, to answer their hypothesis regarding student interactivity, attendance and satisfaction as well as instructor and student productivity. Based on the combination of structured observation and self-reporting in a factorial controlled study, they gained valuable data on the usability of the computerbased atlas.

The use of ethnography in usability studies, human computer interaction and software design, indicate the potential of using SGE for ethnographic research, where essentially, any design situation involves an element of simulation of the intended design in some form.

\section{UNDERSTANDING GAMING AS A CULTURE}

In his famous 1871 definition, Edward B. Tylor, a founding figure in anthropology, defines culture as "that complex whole which includes knowledge, belief, art, morals, law, custom, and any other capabilities and habits acquired by man as a member of society" [Tylor, 1871/1958, as cited by $11, \mathrm{p} 1]$.

In qualitative research, the concept of culture refers to "cohesive behavior within any social grouping from a neighborhood to a work group" [12, p. 12]. Games, and for the last three to four decades, Video Games, have been embedded in society, where they are not only played by children or teenagers but have been used by all ages of people in many activities from entertainment, health, to education. A study by Yates and Littleton [13] has presented evidence of the importance of viewing computer gaming from a social and cultural perspective. Several studies have illustrated the importance of understanding and studying the gaming culture by looking at the gamers and their experience, which benefits in understanding the impact of games, game aesthetics, game play, as well as the creation of methodology in studying games [14-16].

Multiplayer games such as Mario Party, racing games, or shooting games create a social environment of excitement, competitiveness or teamwork. Multiplayer online games construct networks of gamers throughout the World, where strangers can become allies, which may continue as friends. The creation of portable devices such as Nintendo Dual Screen (NDS) and the PlayStation Portable (PSP) for individual gaming supports network play and is also becoming a social activity. These factors show that gaming is now a culture that is part of society and is important to understand from a social perspective, but it is also often undertaken in dispersed and virtual social groups.

Ethnography is an appropriate method for these research projects, in studying a group of people that have accepted games as a part of their life. The aim is to capture reactions, moods, and feelings in the most natural gaming experience possible. This includes documenting not just what the gamers say but also movements, facial expressions, and emotions that might develop during game play. Ethnography accepts that, as humans, our words sometimes do not portray our actions, and the difference between our opinions and our behaviour is also significant.

\section{SimUlated GAMING ENVIRONMENT FOR ETHNOGRAPHY RESEARCH.}

"Talking about 'the field' in ethnography is no longer easy to do as it once was. In a way, the field is everywhere and nowhere at the same time. A field site can be referred to as a location of doing research but avoids referring it as a monolithic place of research" [17, p. 14].

"Settings are not a naturally occurring phenomena, they are constituted and maintained through cultural definition and social strategies. Their boundaries are not fixed but shift across occasion, to one degree or another, through processes of repetition and negotiation. A setting is a named context in which phenomena occur that might be studied from any number of angles" [18, p. 41].

In the gaming industry, ethnography has been used in various studies to understand the social aspect of gaming particularly in Multiplayer Online Gaming and games for education [19-20]. Boellstorff [11] claims that anthropology benefits game studies in understanding games cultures, social behavior in gaming, and discusses the use of participant observation for investigating games and culture. It has been discussed, in conducting ethnography research, that the researcher has to be in the "field" and immerse themselves in the natural environment of the culture to be studied.

Here, these researchers would like to argue that the gaming experience is flexible as it depends on each individual gamer. A natural gaming environment could be a friend's house, a cybercafé, in the park, or in the gamers own bed room. Due to the creation of portable consoles, gamers can also play games on the bus, in the class rooms, or at the office so that the social aspect of gaming is woven into every aspect of life. Creating a simulated gaming environment that is comfortable for the gamers and the convenience of having 
all the games media to be studied assessable, could be another method in conducting ethnographic research for gaming.

Research has already been undertaken where "living laboratories" (natural users environment) were created to enable ethnographic research and observation studies [21]. MIT Living Labs and 'the place lab' were created as an environment where experts can study, develop and test technologies and design strategies [22]. Another natural setting laboratory developed by Philips Research is the Experience Lab, where proposed new technologies and applications can actually be tested and experienced [23]. A recent research study on video games in Singapore, by Bolt|Peters came up with what they called a "Simulated Native Environment" to cater for the privacy issue faced in entering the house of gamers. The gamers were asked to sit in the loft office and given a desk with a laptop, a microphone headset, and a webcam. The environment of the loft was quite homely, and they were asked to play the game as if they are at home and the think-aloud method was executed. An observation team was sitting in the next room to observe and hear the gamers' comments [24].

However, most of these studies are to test the software or hardware of a certain technology including the games themselves or the platform. Observations are done quietly and the researcher is usually in another room. Using SGE and ethnography to gain insights into human's feelings and behavior have yet to be explored deeply as research of theory development rather than artifact testing.

Here, a section of the HCI lab at Auckland University of Technology (AUT) has been transformed into a simulated gaming environment that is comfortable and natural for the gamers. This is to enable the researchers to conduct ethnographic research on gamers and games media. Some choice of equipment and games are accessible to the gamers in this simulated environment. The simulation would not be dissimilar to inviting the gamers to play at a friend's house.

\section{ANSWERING THE CHALLENGES OF ETHNOGRAPHY}

There are a few concerns in conducting ethnography research that could be answered when conducted with SGE.

\section{A. Time}

In ethnographic research, time is always a concern in conducting field work, analyzing data and writing up materials. However, Myers stated that the best time to conduct ethnographic research is probably during "one's doctoral studies" [3, p. 3], which is the first authors' research situation. Both researchers consider that the amount of time going to the "field" for observation should be more manageable due to the SGE. The SGE would make access to the gamers and the gaming material more organised. Studies on games or gamers behavior would depend on the game play and the amount of time the participants' take to finish a stage in the game. Other than the traditional note taking process, all observations and interviews will be recorded (i.e. video or audio taped), data would be reviewed and summarized simultaneously as the study is being run to cater for the volume of data gathered. This also is to resolve the time issue in performing ethnography analysis and writing.

\section{B. Availability and Accessibility}

Another concern of ethnography is access and availability to the participants and gaming media. Gaining access to participant homes or obtaining participants that have all the game media required for the research might be challenging, and in the second authors research project impossible to achieve. Conducting the research in a SGE, where all the research equipment and gaming media are available would solve some of these issues. The participant and the researcher will be in an area that is comfortable, safe and accessible. All matters related to privacy, consent, confidentiality, and other ethics consideration can be managed for this research in this environment.

\section{Authority of Data}

The storytelling nature of ethnography writing as well as the fact that the primary instrument in ethnography research is the researcher her/his self does lead to data being influenced by the researcher's point of view and beliefs, and this is made explicit. Hence, it is important for ethnographers to have their "data recognized as having authority" [1].

Klein and Myers [25] Principle's for Interpretive Field Research, which can be applied when reviewing data, is referred to, to resolve any predicted issues relating to authority of data. According to them, the researcher would need to be sensitive to several factors which include a) understanding that they could be a "contradiction between research design and actual findings", b) understanding the "possibility of differences in interpretation among participants as are typically expressed in multiple narratives or stories of the same sequenced of events during study" c) understanding the "possibility of biases and systematic distortion in the narratives collected from the participant" (p.72).

If all the above principles are followed in the SGE ethnography study, the authority of the data should be supported.

\section{ONGOING ETHNOGRAPHIC SGE RESEARCH}

This paper is based on two ethnographic research studies that are currently in progress at the SGE in AUT. The first is a PHD research project on the intrinsic motivation of gamers when playing games of a certain genre on different screen sizes. The second is a research project is a driving simulator for high speed / high cognitive load research.

\section{A. The Effect of Gamers Intrinsic Motivation when Playing Games of a Certain Genre on different Screen Sizes.}

This research has created a SGE where a section of the HCI lab has been turned into a comfortable gaming room. The room is included with comfortable furniture (sofa's, cushions, beanbags,) and equipped with games consoles (Nintendo Wii, Nintendo Ds), video games (Wii sport, Big Brain Academy, Super Mario Bros, Mario Kart), speakers and a 40 inch television screen. The ambience is created to make the gamers feel that they are in their in their natural environment for playing games. 
This research aims to create a new theory that would measure gamers' intrinsic motivation when playing video games of a certain genre on different screen sizes. It focuses on games that might bring a positive impact to the community such as education games, puzzle games and the action platform game genre. Identifying whether there is any difference in gamers' intrinsic motivation when playing games of a certain genre on different screen sizes, might determine whether screen sizes would be a factor in motivating gamers' to play these positive games. This research also aims to determine the usage of suitable game platform or consoles accordance to suitable areas such as health or education.

The participants chosen for the research are gamers that (a) have sufficient knowledge and skill in playing video games and do not need training in playing the consoles (participant has experience in using the game controllers and familiar with game play), (b) 18 to 45 years old considering that $78 \%$ of gamers in New Zealand are 18 years or older and the average age of gamers is 33 years [26].

The data gathering methods for this research are Participant Observation and Ethnographic Interviews.

\section{1) Participant-Observation}

Participant observation is a method where the researcher collects data by observing and participating in the activity of the person that is being studied. The aim is to produce a deep understanding of social interaction and encourage the participant to converse in a more natural environment [4, 17]. It involves data gathering by "watching, observing and talking to participant in order to discover their interpretations, social meanings and activities" [1, p. 59]. The sessions are recorded (e.g. video-taped) with participants' consent, which will be transcribed for analysis.

\section{2) Ethnographic Interviews}

In ethnography, interviews provide an opportunity for the researcher to ask direct questions and gain access to personal thoughts and experiences. An ethnographic interview is more informal in nature and should not feel like an interrogation [17]. At the end of the observation session a one-to-one interview is conducted. The interviews are done with openended questions which are flexible, deep and expansive and usually conversational like [17, 27]. All interviews will be audio-taped as a permanent record for analysis.

\section{Preliminary Results: Conducting an Ethnographic} Research Study using SGE.

So far there have been nine gamers that participated over a total of approximately 75 hours in the study. They were all male gamers between the ages of 18 to 36 years old. Five of them have been involved in both single player study and multiplayer study, and the rest participated in only the multiplayer study. All gamers played Mario Kart WII and Mario Kart DS. Some other games that the participants also tried were Zelda Crossbow for the WII and Xbox KINECT Sport games. The game sessions were videotaped and participants were encouraged to talk-aloud, express their feelings and to enjoy themselves.
In observing the gamers, at the beginning of the sessions, it was clear from the gestures of the participants that they were anxious about the surrounding and procedures that were included in the observation protocol and consent forms. However, once game play starts, the surrounding had no effect on the gamers. They immediately showed enthusiasm (e.g. shouting, cursing and laughing) and concentrated on the game. One of participants, took off his shoes to be more comfortable while another participant started stomping his feet in excitement. All participants seem to forget that they are in a simulated environment and being videotaped. They preferred the lighting of the room to be dimmed.

After the game sessions, the participants were asked to reflect on their game playing experience. Most of the participants commented that they felt comfortable with the environment during the game session, and did not notice that they were in a SGE, essentially an informal part of a much larger and more formal office environment.

During the multiplayer sessions, the game play was even noisier than the single player sessions, with friendly hackling and sense of competition. Having other friends to join the session or to watch the game made the study more interesting and fun.

Participant 4 commented that "I did not notice that I was in a simulated environment or office space. I did not even feel that I was being videotaped. I was enjoying the game."

Participant 9 expressed that "At first, when entering the office space and filling in the consent forms, I was a bit nervous. However, once I started playing the game and competing with my friends, all that matters was to have fun with friends and trying to win the game."

In conclusion, the preliminary findings on using SGE as a "field" for ethnography research in observing gamers playing a game is plausible since the gamers feel that they are in their natural environment.

\section{B. Driving Simulator for high speed/high cognitive load research}

The Second author has built a driving simulator, to conduct research to support the design of an actual World land speed record vehicle project (JetBlack). The paraphernalia that surrounds the space includes the design drawings and photo's of the real vehicle production. The 3D gaming platform has a well-developed physics engine to give a feeling of 'real' movement and is an important part of the experience. Subtle changes to texture mapping and sound effects are also proving to create a greater feeling of 'reality', but there is very little chance that any participant will completely become immersed. So the idea of using gamers to test this simulation is an important concept. Gamers are more likely to be able to imagine themselves driving this vehicle as escapism is part of the gaming experience. The competitive nature of games is also likely to keep them serious about the task, and whilst 'crashing' will cause 
embarrassment it will not cause significant injury or loss of life, so how seriously they take the experience is an important part of the interpretation of the observations and opinions we collect. A leader board for fastest runs is currently on our 'to do' list.

Data is being collected from Video recording participants driving and having very informal discussions with them afterward. Significant events or texts are identified through fairly generic indicators used in ethnography; repetition between or within participants comments / observed behaviour, strength of opinion / observed mood, participants explicit interpretations or explanations, participants sharing historical accounts or stories, and serendipity. Credence is given primarily to unprovoked and spontaneous texts.

So far only a few participants have been involved in the 'pilot' testing stage of the project, but have offered valuable insight into how to improve the 'reality' of the simulation, and as the development has progressed there have been increasingly encouraging comments about the level of immersion the environment is evoking. The important nature of this SGE is that it is the only available 'field' that there is, so the positive comments from participants, and the continuous positive trend in comments will assist in building a 'valid' SGE suitable to study the controls and visual display outputs in the cockpit.

As the controls continue to develop, such as prototyping a HUD (heads up display) and yoke with appropriate control surfaces (places for buttons / switches / analogue control) using fast prototyping technology (3D printer), and as the physics and graphics get closer to the potential reality, then the experience will inevitably get more real. So the encouraging comments and level of immersion felt by participants in these early stages is supporting the rigour of the ethnographic methodology.

\section{CONCLUSION}

This paper has discussed ethnography particularly its usage in the area of information systems and gaming. The aim of these researchers is to use a simulated gaming environment as the "field" of study. More results from the research that are discussed in this paper will be presented in future writing.

\section{REFERENCES}

[1] J. D. Brewer, Ethnography, 1st ed. Philadelphia: Open University Press, 2000

[2] M. Genzuk, (1999, 20 June). A Synthesis of Ethnographic Research. Available:http://wwwbcf.usc.edu/ genzuk/Ethnographic_Research.html

[3] M. Myers, "Investigating Information Systems with Ethnographic Research," Commun. AIS, vol. 2, pp. 1-20, 1999.

[4] D. M. Fetterman, Ethnography : Step by Step, 2nd ed. vol. 17. California: SAGE Publication, Inc., 1998.

[5] J. Hughes, et al., "The Role of Ethnography in Interactive Systems Design," Interactions, vol. 2, pp. 56-65, 1995.

[6] J. Hughes, et al., "Moving Out from the Control Room: Ethnography in System Design" in Proceedings of the 1994 ACM conference on Computer Supported Cooperative Work, Chapel Hill, North Carolina, United States, 1994, pp. 429-439.
[7] J. Burke and A. Kirk, (2001, 15 July). Ethnographic Methods Available: http://otal.umd.edu/hci-rm/ethno.html

[8] D. R. Millen, "Rapid Ethnography: Time Deepening Strategies for HCI Field Research," in Proceedings of the 3rd conference on Designing interactive systems: processes, practices, methods, and techniques, New York City, New York, United States, 2000, pp. 280 286.

[9] L. B. Gouveia and F. R. Gouveia, "Evaluative Ethnography and Systems Design: Can It Also be Used to Assess Presence," presented at the Presentation of the Fifth Annual International Workshop PRESENCE 2002, International Society for Presence Research, Universidade Fernando Pessoa, Porto, Portugal, 2002.

[10] H. P. Lehmann, et al., "An Ethnographic, Controlled Study of the Use of a Computer-based Histology Atlas during a Laboratory Course," Journal of the American Medical Informatics Association, vol. 6, pp. 38-52, 1999.

[11] T. Boellstorff, "A Ludicrous Discipline? Ethnography and Game Studies," Games and Culture, vol. 1, pp. 29-35, January 1, 2006.

[12] A. Holliday, Doing and Writing Qualitative Research, 2nd ed. London: SAGE Publlication 2007.

[13] S. J. Yates and K. Littleton, "Understanding Computer Game Cultures: A Situated Approach," Information, Communication \& Society, vol. 2, pp. 566-583, 1999.

[14] C. A. Steinkuehler, "Why Game (Culture) Studies Now?," Games and Culture, vol. 1, pp. 97-102, January 1, 2006.

[15] E. Aarseth, "Playing Research: Methodological Approaches to Game Analysis," in Melbourne DAC - the 5th International Digital Arts and Culture Conference, Melbourne, Australia, 2003.

[16] S. Lammes, "Approaching Game-studies: Towards a Reflexive Methodology of Games as Situated Cultures," in Situated Play, Proceedings of DiGRA 2007 Conference, Tokyo, 2007, pp. 25-30.

[17] J. M. Murchison, Ethnography Essentials : Designing, Conducting and Presenting your Research. San Francisco: Jossey-Bass, 2010.

[18] M. Hammersley and P. Atkinson, Ethnography : Principle in Practice, 2nd ed. London and New York: Routledge Taylor and Francis Group, 2002.

[19] N. Ducheneaut and R. J. Moore, "More than just 'XP': Learning Social Skills in Massively Multiplayer Online Games," Interactive Technology and Smart Education, vol. 2, pp. 89-100, 2005.

[20] Y. Wang and S. D. Mainwaring, "Ethnography at Play: An Exploratory Case Study of Chinese Users' Experience in and around Online Games," in Proceedings of CHI08 Workshop on Evaluating User experience in Games, Florence, Italy, 2008, pp. 1 - 5.

[21] J. O. Pierson and B. Lievens, "Configuring Living Labs For A 'Thick' Understanding Of Innovation," in Ethnographic Praxis in Industry Conference Proceedings, 2005, pp. 114-127.

[22] S. S. Intille, et al., "A Living laboratory for the Design and Evaluation of Ubiquitous Computing Technologies," presented at the CHI '05 extended abstracts on Human factors in computing systems, Portland, OR, USA, 2005.

[23] (2011, 20 June). ExperienceLab. Available: http://www.research.philips.com/focused/experiencelab.html.

[24] N. Bolt and T. Tulathimutte, (2009, 21 October). Researching Video Games the UX Way - A Look at How Bolt|Peters Researched Usability for Spore.Available: http://www.boxesandarrows.com/view/researching-video

[25] H. K. Klein and M. D. Myers, "A Set of Principles for Conducting and Evaluating Interpretive Field Studies in Information Systems," MISQ., vol. 23, pp. 67-93, 1999.

[26] Jeffrey E. Brand, "Interactive New Zealand 2010," Bond University, Interactive Games and Entertainment Association, Gold Coast, Australia 2010

[27] M. Denscombe, The Good Research Guide for Small-Scale Socia Research Project, 2nd ed. Philadelphia: Open University Press, 2003. 
Noor Fardela Zainal Abidin holds a teaching post at the Graphics and Multimedia Department, College of Information Technology, University Tenaga Nasional (UNITEN), Malaysia, and is currently taking a three year leave of absence to study her PhD at AUT, accompanied by her husband and daughters.

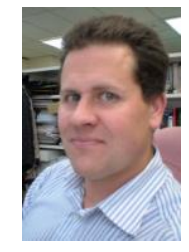

Robert Wellington is the Director of the Human Computer Interaction Laboratory at AUT University. He has been teaching in the HCI area at the undergraduate and post graduate level for 8 years and teaching Research Methods at the post graduate level for about the same period of time. He has moved into researching games in some ways because his students in the HCI papers seem to learn far more readily about theory and usability processes in gaming environments rather than traditional database and information systems. It's also where all the cool toys are. 